https://helda.helsinki.fi

\title{
Long-term outcome and its predictors in giant cell myocarditis
}

\section{Ekström, Kaj}

2020-07-02

Ekström , K , Räisänen-Sokolowski , A , Lehtonen , J \& Kupari , M 2020 , ' Long-term outcome and its predictors in giant cell myocarditis ' , European Journal of Heart Failure , vol. 22 , no. 7 , pp. 1283-1284 . https://doi.org/10.1002/ejhf.1953

http://hdl.handle.net/10138/320747

https://doi.org/10.1002/ejhf.1953

cc_by_nc_nd

publishedVersion

Downloaded from Helda, University of Helsinki institutional repository.

This is an electronic reprint of the original article.

This reprint may differ from the original in pagination and typographic detail.

Please cite the original version. 
doi:10.1002/ejhf.1953

Online publish-ahead-of-print 28 July 2020

\section{Long-term outcome and its} predictors in giant

cell myocarditis. Letter regarding the article

'Long-term outcome and its predictors in giant cell

\section{myocarditis'}

In 2016, we reported in your Journal ${ }^{1}$ on the outcome of 46 patients with giant cell myocarditis (GCM) in Finland. Later, we encountered incidental cases of GCM where the diagnosis was converted to cardiac sarcoidosis (CS) at post-transplant or post- mortem examinations. This forced us to re-evaluate all GCM diagnoses made since 1991 in our country. ${ }^{2}$ Altogether 26 of the 46 cases were reclassified as CS, most commonly due to recognition, with help of immunochemistry, of sarcoid granulomas missed or misinterpreted on original microscopy (Figure 1). The 5-year estimate (95\% confidence interval) of transplant-free survival, having been $42 \%(39-56 \%)$ in our 2016 report, ${ }^{1}$ was $25 \%(0-40 \%)$ in the 20 patients keeping the GCM diagnosis. In Cox regression analysis involving all 46 patients, GCM predicted the occurrence of death or transplantation with a hazard ratio $(95 \%$ confidence interval) of 2.68 (1.22-5.87, $P=0.014)$. In bivariate Cox analyses, biomarkers of cardiac injury and dysfunction, as well as at least moderate myocardial necrosis or fibrosis, predicted the outcome independent of the diagnosis of CS or GCM. The hazard ratios are shown in Table 1 .

Cardiac sarcoidosis and GCM are known to share clinical manifestations and characteristics of histopathology. ${ }^{3-5}$ Their differentiation on microscopy of tiny endomyocardial samples can be very difficult, sometimes nearly impossible. Magnetic resonance imaging and ${ }^{18} \mathrm{~F}$-fluorodeoxyglucose ( $\left.{ }^{18} \mathrm{~F}-\mathrm{FDG}\right)$ positron emission tomography can be of some help as mediastinal lymphadenopathy and ${ }^{18} \mathrm{~F}-\mathrm{FDG}$ uptake suggest CS and mediastinal lymph node biopsy may expose sarcoidosis histology. Distinction of CS and GCM is complicated further by the fact that researchers divide on the diagnostic role of myocardial granulomas. Some, like us, consider granulomas and GCM mutually
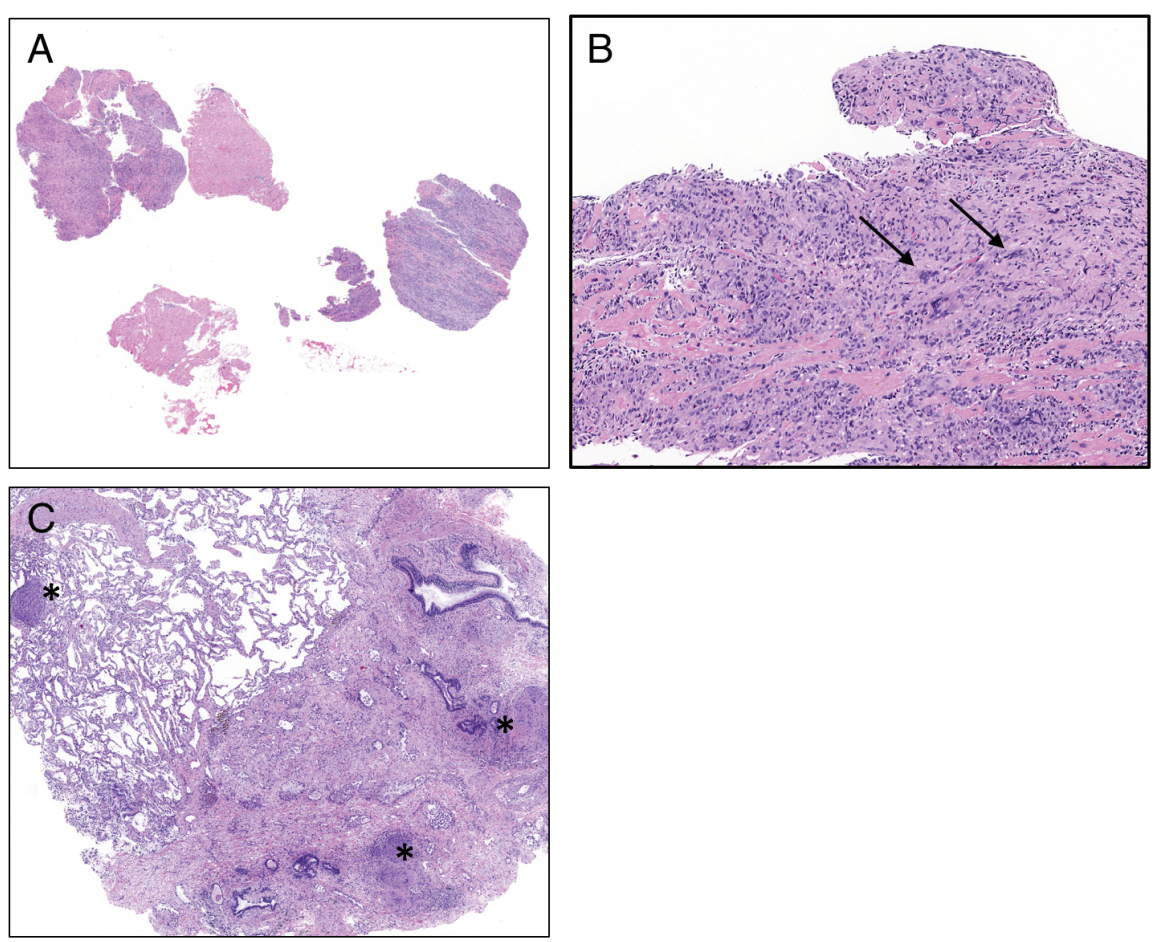

Figure 1 An example of cardiac sarcoidosis (CS) initially mistaken for giant cell myocarditis. (A) Shows five pieces of endomyocardial tissue acquired at the same biopsy session from a patient with atrioventricular conduction block. Two pieces look histologically normal while three show diffuse inflammation and myocyte injury. High magnification (B) reveals small multinucleated giant cells (arrows) and numerous infiltrating eosinophils but no epithelioid-cell granulomas. A diagnosis of giant cell myocarditis was made. (C) Demonstrates lung cryobiopsies taken later from the same patient. Several well-formed granulomas $(*)$ diagnostic of sarcoidosis are seen. Cardiac involvement was reclassified as cardiac sarcoidosis. 
Table 1 Bivariate Cox analyses

\begin{tabular}{|c|c|c|c|c|}
\hline Predictor & $\begin{array}{l}\text { Model } 1 \\
(\mathrm{e} / \mathrm{n}=25 / 45)\end{array}$ & $\begin{array}{l}\text { Model } 2 \\
(e / n=16 / 36)\end{array}$ & $\begin{array}{l}\text { Model } 3 \\
(e / n=19 / 38)\end{array}$ & $\begin{array}{l}\text { Model } 4 \\
(\mathrm{e} / \mathrm{n}=17 / 37)\end{array}$ \\
\hline GCM diagnosis & $2.39(1.02-5.60)^{*}$ & $1.98(0.66-5.96)$ & $1.12(0.37-3.36)$ & $4.21(1.47-12.05)^{\text {*ek }}$ \\
\hline LVEF, per $+5 \%$ & $0.91(0.78-1.01)$ & - & - & - \\
\hline NT-proBNP, per $+1000 \mathrm{ng} / \mathrm{L}$ & - & $1.06(1.02-1.09)^{* *}$ & - & - \\
\hline cTnT > 85 ng/L (median) & - & - & $4.28(1.30-14.04)^{*}$ & - \\
\hline Grade $2-3$ necrosis or fibrosis ${ }^{\mathrm{a}}$ & - & - & - & $7.61(2.38-24.39)^{\S}$ \\
\hline
\end{tabular}

The data are hazard ratios ( $95 \%$ confidence interval).

cTnT, cardiac troponin T; e/n, endpoint events/total numer of patients with sufficient data available for the model; GCM, giant cell myocarditis; LVEF, left ventricular ejection fraction; NT-proBNP, N-terminal pro brain natriuretic peptide.

${ }^{*} P<0.05$;

** $P<0.01$;

$\S p<0.001$.

a Scale $0-3$ on myocardial microscopy

exclusive $^{2-4}$ but others disagree. ${ }^{5}$ It is also possible that CS and GCM are not fully different entities but intimately related diseases or even partially overlapping segments of a single disease spectrum. The reader who favours their dichotomy should know, however, that the study population of our 2016 paper $^{1}$ was a mix of CS and GCM by our current criteria and that the lower 5-year survival estimate reported here better represents true GCM.

\section{Kaj Ekström*, \\ Anne Räisänen-Sokolowski, \\ Jukka Lehtonen, and \\ Markku Kupari}

Heart and Lung Center, Helsinki University

Hospital, Helsinki, Finland

*Email: kaj.ekstrom@helsinki.fi

\section{References}

1. Ekström K, Lehtonen J, Kandolin R, RäisänenSokolowski A, Salmenkivi K, Kupari M. Long-term outcome and its predictors in giant cell myocarditis. Eur J Heart Fail 2016;18:1452-1458.

2. Ekström K, Räisänen-Sokolowski A, Lehtonen J, Nordenswan HK, Mäyränpää MI, Kupari M. Idiopathic giant cell myocarditis or cardiac sarcoidosis? A retrospective audit of a nationwide case series. ESC Heart Fail 2020;7:1362-1370.

3. Davies MJ, Pomerance A, Teare RD. Idiopathic giant cell myocarditis - a distinctive clinico-pathological entity. Br Heart J 1975;37:192-198.

4. Litovsky SH, Burke AP, Virmani R. Giant cell myocarditis: an entity distinct from sarcoidosis characterized by multiphasic myocyte destruction by cytotoxic $T$ cells and histiocytic giant cells. Mod Pathol 1996;9:1126-1134.

5. Okura Y, Dec GW, Hare JM, Kodama M, Berry GJ, Tazelaar HD, Bailey KR, Cooper LT. A clinical and histopathologic comparison of cardiac sarcoidosis and idiopathic giant cell myocarditis. J Am Coll Cardiol 2003;41:322-329. doi:10.1002/ejhf.1826

Online publish-ahead-of-print 15 April 2020

Evaluating biomarkers as predictors of cancer therapy cardiotoxicity: all you need is a meta-analysis?. Letter regarding the article

'Troponins and brain natriuretic peptides for the prediction of cardiotoxicity in cancer patients: a meta-analysis.'

We read with great interest the meta-analysis by Michel et al. ${ }^{1}$ who investigated troponins and B-type natriuretic peptides (NPs) as indicators of cardiac damage and predictors of systolic dysfunction in adult patients receiving anticancer drugs (anthracyclines, HER2 inhibitors or their combination, myeloablative therapy for stem cell transplantation, radiotherapy, or other chemotherapy regimens). Herein, we would like to highlight some possible issues with their analysis, which may inform future research on this topic.

The literature search was done in November 2018. It did not include recent significant evidence such as the study reporting that the risk of cardiac dysfunction over 4 years is two-fold higher when high-sensitivity troponin $\mathrm{T}$ (hs-TnT) is $>14 \mathrm{ng} / \mathrm{L}$ at the end of anthracycline treatment and that a doubling of $\mathrm{N}$-terminal fragment of pro-B-type NP during therapy is associated with a 1.6 -fold higher risk of cardiac dysfunction. ${ }^{2}$ Similarly, the Authors did not consider a novel and promising field of research, namely troponins as indicators of myocarditis by immune checkpoint inhibitors. ${ }^{3}$ Furthermore, the whole analysis revolved around a comparison between normal and elevated troponin levels, but we are not entirely convinced of the opportunity to pool together troponin $\mathrm{T}$ and I assays of different generations, with highly different upper reference values (e.g. $14 \mathrm{ng} / \mathrm{L}$ for hs-TnT and $80 \mathrm{ng} / \mathrm{L}$ for troponin I with the I-STAT assay). ${ }^{4}$ We may add that reducing plasma troponin values to a binary variable (elevated vs. normal) is likely to underexploit the information conveyed by a troponin dosage. Troponin increase from baseline to the end of treatment might further refine prognostic stratification, also because highsensitivity assays have a low intra-individual coefficient of variation, which means that random fluctuations are small. Troponin levels are reliably associated with the severity of ongoing myocardial damage. ${ }^{5}$ Finally, reduced left ventricular ejection fraction is only a surrogate endpoint, and biomarkers should be preferably evaluated as predictors of more clinically robust outcome measures, such as heart failure hospitalization or cardiovascular mortality.

In summary, Michel et al. should be congratulated for their effort to provide a synthetic assessment of the sparse and heterogeneous evidence on troponins and NPs as indicators and predictors of cardiotoxicity. Nonetheless, their analysis is burdened by some limitations that could be overcome only by pooling together individual patient data, or by designing prospective studies aiming to answer specific questions. 